\title{
Genome-wide identification, characterization and expression profiling of gibberellin metabolism genes in jute
}

Ummay Honi ${ }^{1 \dagger}$, Md. Ruhul Amin ${ }^{1+}$, Shah Md Tamim Kabir ${ }^{1}$, Kazi Khayrul Bashar ${ }^{1}$, Md. Moniruzzaman ${ }^{1}$, Rownak Jahan², Sharmin Jahan², Md. Samiul Haque ${ }^{1,3}$ (I) and Shahidul Islam ${ }^{1,3^{*}}$

\begin{abstract}
Background: Gibberellin (GA) is one of the most essential phytohormones that modulate plant growth and development. Jute (Corchorus sp.) is the second most important source of bast fiber. Our result has shown that exogenous GA can positively regulate jute height and related characteristics which mean increasing endogenous GA production will help to get a jute variety with improved characteristics. However, genes involved in jute GA biosynthesis have not been analyzed precisely.

Results: Genome-wide analysis identified twenty-two candidate genes involved in jute GA biosynthesis pathway. Among them, four genes- COCPS, CoKS, CoKO and CoKAO work in early steps. Seven CoGA20oxs, three CoGA3oxs, and eight GA2oxs genes work in the later steps. These genes were characterized through phylogenetic, motif, gene structure, and promoter region analysis along with chromosomal localization. Spatial gene expression analysis revealed that 11 GA oxidases were actively related to jute GA production and four of them were marked as key regulators based on their expression level. All the biosynthesis genes both early and later steps showed tissue specificity. GA oxidase genes were under feedback regulation whereas early steps genes were not subject to such regulation.
\end{abstract}

Conclusion: Enriched knowledge about jute GA biosynthesis pathway and genes will help to increase endogenous GA production in jute by changing the expression level of key regulator genes. CoGA20ox7, CoGA3ox2, CoGA2ox3, and CoGA20x5 may be the most important genes for GA production.

Keywords: Jute, Gibberellin, Natural fiber, Biodegradable, Tissue specificity, Feedback regulation

\footnotetext{
* Correspondence: nshahidul@gmail.com; shahidul@jutegenome.org

†Ummay Honi and Md. Ruhul Amin contributed equally to this work.

'Basic and Applied Research on Jute Project, Bangladesh Jute Research Institute, Manik Mia Avenue, Dhaka 1207, Bangladesh

${ }^{3}$ Bangladesh Jute Research Institute, Manik Mia Avenue, Dhaka 1207, Bangladesh

Full list of author information is available at the end of the article
}

(c) The Author(s). 2020 Open Access This article is licensed under a Creative Commons Attribution 4.0 International License, which permits use, sharing, adaptation, distribution and reproduction in any medium or format, as long as you give appropriate credit to the original author(s) and the source, provide a link to the Creative Commons licence, and indicate if changes were made. The images or other third party material in this article are included in the article's Creative Commons licence, unless indicated otherwise in a credit line to the material. If material is not included in the article's Creative Commons licence and your intended use is not permitted by statutory regulation or exceeds the permitted use, you will need to obtain permission directly from the copyright holder. To view a copy of this licence, visit http://creativecommons.org/licenses/by/4.0/ The Creative Commons Public Domain Dedication waiver (http://creativecommons.org/publicdomain/zero/1.0/) applies to the data made available in this article, unless otherwise stated in a credit line to the data. 


\section{Background}

Gibberellin (GA), identified by Dr. E. Kurosawa in 1926, is one of the key phytohormones for plant growth and development. This classical phytohormone participates in different physiological processes like seed germination [1, 2], shoot elongation [3], leaf expansion [4], flower development [5], and fruit- senescence [6]. It ultimately induces cell elongation and division; moreover, it accumulates starch [7] and thus has the ability to influence overall plant growth. GAs form a large family of diterpene hormones with 130 members identified in plants, fungi and bacteria [8]. All of them have either 19 or 20 carbon atoms and classified as C19-GAs and C20-GAs respectively. Though plants have hundreds of GAs, only a few of them such as $\mathrm{GA}_{1}$ and $\mathrm{GA}_{4}$ are bioactive [8].

GA biosynthesis pathway which produces active GAs from geranylgeranyl diphosphate (GGDP, a common precursor of terpenes in plants), is well defined in model plants and most of the genes encoding GA biosynthesis enzymes have been identified $[9,10]$. The pathway is distinctly separated into early and later steps [11]. Early steps include conversion of GGDP to $\mathrm{GA}_{12}$ whereas later steps include conversion of $\mathrm{GA}_{12}$ to GAs. In the first step, GGDP is converted to ent-kaurene by two enzymes from terpene synthases (TPSs) family named ent-copalyl diphosphate synthase (CPS) and ent-kaurene synthase (KS). Then ent-kaurene is oxidized to $\mathrm{GA}_{12}$ by the activity of another two enzymes named ent-kaureneoxidase (KO) and ent-kaurenoic acid oxidase (KAO), from cytochrome P450 monooxygenases (P450s). In the later steps, GA20 oxidase and GA3 oxidase catalyze stepwise oxidation to produce various GA intermediates and bioactive GAs like $\mathrm{GA}_{1}, \mathrm{GA}_{4}$ while $\mathrm{GA} 2$ oxidase converts them to inactive GAs such as $\mathrm{GA}_{8}, \mathrm{GA}_{34}$ respectively [12].

All the early steps genes are encoded by single or few genes [13]. Though some of the plants have multiple homologous genes, only one of them participates in GA metabolism. For instance, rice has three copies of OsCPS and 11 copies of OsKS-like gene families. However, only OsCPS1 and OsKS1 participate in entkaurene biosynthesis [14]. On the contrary, GA oxidases are encoded by small gene families [10, 15] and show different expression pattern in different organs [16] and have a distinct functional role. As an example, MaGA3ox4 has higher expression in young banana fruits while it is lowly expressed in mature fruits. Similarly, the expression level of MaGA20ox3 is high in leaves, bracts, and young fruits but low in roots, false stems and mature fruits [17]. Moreover, some of the GA oxidases maintain GA homeostasis in the plant through feedback regulation $[15,18,19]$ and feed forward regulation [20-22]. However, early steps genes i.e. CPS, $K S, K O$, and $K A O$ are not subject to feedback control $[16,23]$ in plants.
Later steps genes are more important in comparison to early steps genes in the regulation of endogenous bioactive GA level [11]. For example- loss of function of GA20 oxidase and GA3 oxidase caused dwarf phenotype, such as Green Revolution sd-1 [10, 19, 24] whereas no phenotypic alteration was found in the transgenic plants overexpressing AtCPS and AtKS [25]. On the other hand, ectopic expression of GA20ox resulted into taller plants and larger organs in Arabidopsis [26, 27] potato [28], tobacco [29], and maize by increasing endogenous GA levels. Likewise, the dwarf phenotype with dark green leaves was evidenced in transgenic plant over expressing JcGA2ox6 [30].

Jute, known as golden fiber, is one of the longest and cheapest natural fibers, covering $\sim 80 \%$ of global bast fiber production [31]. It is well known for its durability and versatility. Most importantly, it is biodegradable, renewable and eco-friendly [32]. Hence, jute and jute products are gaining popularity globally and expected to increase by $200 \%$ by 2021 [33] which demand more yield. Though both Corchorus olitorius and Corchorus capsularis are commercially cultivated, the primary source of the fiber is Corchorus olitorius since this species is grown in around $80 \%$ jute growing areas in the world. The previous studies showed that exogenous GA spray on jute caused the elongated fiber cell along with longer stem and internode [34]. Also, GA induced cell wall thickness and a higher diameter of fiber cell [35]. Moreover, our experiment stated that GA sprays increased internode length of jute which finally created the taller plant than control (Unpublished data). Therefore, GA plays a crucial role in jute growth and development.

GA metabolism pathway is explained in various plant species, such as Arabidopsis [13, 15, 16], pumpkin [36], rice [10], pea [37], maize [38], Salvia miltiorrhiza [39] and banana [17]. In addition, this knowledge has been extensively used to develop plants having altered GA levels and desired characteristics. For instance- the silencing of GA2 oxidase led to transgenic tobacco with increased height and a higher number of xylem cells [40]. Though scientists have already released the genome of two jute species [41], GA metabolism genes in jute are not identified yet. Here, we explored phylogenetic relationship among identified jute GA biosynthesis genes along with their conserve region, gene structure, chromosomal location and duplication event. Moreover, we investigated the effect of exogenous GA spray on jute growth with the GA inhibitor paclobutrazol (PAC) as a contrast. In addition, we checked their expression in different tissues and observe their tissue specificity to identify genes that may trigger GA biosynthesis in jute. This will pave the way to elucidate GA regulation in jute and have jute variety with better agronomic traits. 


\section{Results}

Identification of GA metabolism pathway genes in jute In order to isolate seven types of GA metabolism genesCPS, KS, KO, KAO, GA20 oxidase, GA3 oxidase, and GA2 oxidase in $C$. olitorius, we retrieved respective sequences from Arabidopsis, banana, and rice (Additional file 1: Table S1) and used those sequences as the query for BLASTP against jute genome sequences. We have found 22 candidate genes including one CPS gene (CoCPS), one $K S$ gene (CoKS), one $K O$ gene (CoKO), one $K A O$ gene (CoKAO), seven GA20ox genes (CoGA 20ox 1-7), three GA3ox genes (CoGA3ox1-3) and eight GA2ox genes (CoGA2ox1-8).

\section{Early steps genes}

Jute genome has single genes for all the four enzymes involved in early steps. After searching Pfam and SMART database we have found that both CoCPS and CoKS enzymes contain Terpene synthase, N-terminal domain, and Terpene synthase family, metal-binding domain. They were located in chloroplast having molecular weight (Mw) $91.81 \mathrm{kDa}$ and $84.15 \mathrm{kDa}$ respectively. Numbers of introns were relatively higher in these two genes, 14 and 11 respectively (Fig. 1). The result was almost similar to Arabidopsis, having 16 introns in both AtCPS and AtKS. Being a member of cytochrome P450, CoKO and CoKAO have p450 domain. CoKO and CoKAO was located in chloroplast and endoplasmic reticulum respectively. The molecular weight of CoKO was $56.24 \mathrm{kDa}$ while it was $58.19 \mathrm{kDa}$ for CoKAO. Both CoKO and CoKAO had eight exons and seven introns (Fig. 1). Predicted isoelectric point (pI) for all these four genes varied from 5.55 to 9.15. Detailed information about these genes is given in Table 1 .

\section{Later steps genes}

Three types of enzymes GA20ox, GA3ox and GA2ox are involved in the later steps of GA biosynthesis pathway. All the three groups of enzymes belong to irondependent oxidoreductase family and contain two conserved domains [2OG-FeII_Oxy (PF00847) and DIOX_N (PF14226)]. These domains were common in all the sequences except CoGA20ox5, where 2OG-FeII_Oxy domain was missing. Their Mw ranges were from 35.06 $\mathrm{kDa}$ to $44.56 \mathrm{kDa}$ with a mean value of $46.00 \mathrm{kDa}$ (Table 1). The lowest isoelectric point was found in CoGA2ox6
(5.03) and the highest in CoGA2ox3 (8.80). All the enzymes were located in the cytoplasm.

In gene structure analysis, we found that GA20 oxidases genes of jute possess two introns and three exons while GA3ox subfamily contained one intron and two exons. Genes from both C-19 GA2ox and C-20 GA2ox subgroups had exons number within 3-4. Some of the members from GAox family-like CoGA3ox3, CoGA2ox1 and CoGA2ox8 had relatively longer introns (Fig. 2).

\section{Phylogenetic and conserved motif analysis of GA metabolism genes in jute Early GA biosynthesis genes}

The phylogenetic analysis revealed that two different protein family, diterpenecyclases (CPS and KS) and Cyt P450 monooxygenase (KO, KAO) were resided in two different branches (Fig. 3a) and four different enzymes remained in four different clades. Moreover, it was demonstrated that early steps enzymes could be separated into monocot and dicot groups.

Motif distribution pattern of these protein sequences showed that both CoCPS and CoKS contained almost similar motifs like 1, 2, 3, 4, 6, 15 and 16 (Fig. 1) since they are from the same protein family. Hence, we speculate that these motifs are specific for diterpene cyclases protein family. However, motif no. 13, 17 and 19 is the distinguishing motif between CoCPS and CoKS where CoCPS contained motif no. 13, 17 and CoKS owned motif no. 19. On the other hand, CoKO and CoKAO proteins shared only one common motif that was motif no. 7. Probably, this was the conserved motif for Cyt P450 monooxygenase protein family. The signature motif for CoKO protein was motif no.18 and for CoKAO these were motif no. 8, 10, 11, 12 and 14. Motif sequences are given in Additional file 1: Table S2.

\section{GA oxidases}

A neighbor-joining phylogenetic tree was constructed with 55 GA oxidases (GA20ox, GA3ox, GA2ox) sequences from Arabidopsis, rice, banana, and jute. The phylogenetic tree was divided into four distinct subgroups- GA20 oxidases, GA3 oxidases, C-19 GA2 oxidases and C-20 GA2 oxidases (Fig. 3b). GA20ox and GA2ox had comparatively larger group than GA3ox. For example-Arabidopsis, rice, banana, and jute had 5, 8, 10 , and 7 copies of GA20ox respectively whereas they had 4, 2, 4, and 3 copies of GA3ox respectively.

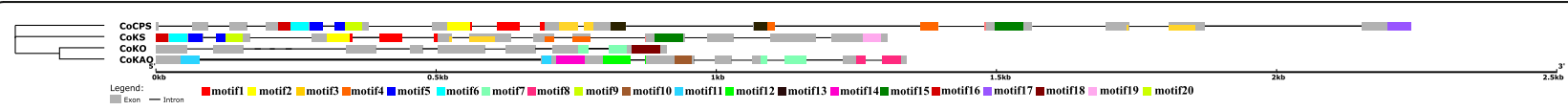

Fig. 1 Distribution of conserved motifs and comparative gene structure analysis among early steps genes of jute GA biosynthesis pathway. Twenty conserved motifs were identified for all the four genes using online tool MEME and showed by different colored boxes. Intron exon distributions were done by GSDS tool. Introns and exons are represented by black lines and ash colored boxes respectively 
Table 1 Sequence features of GA metabolism genes in Corchorus olitorius

\begin{tabular}{|c|c|c|c|c|c|c|c|}
\hline $\begin{array}{l}\text { Gene } \\
\text { name }\end{array}$ & $\begin{array}{l}\text { Accession } \\
\text { number }\end{array}$ & $\begin{array}{l}\text { Coding sequence length } \\
\text { (bp) }\end{array}$ & $\begin{array}{l}\text { Intron } \\
\text { (no.) }\end{array}$ & $\begin{array}{l}\text { Exon } \\
\text { (no.) }\end{array}$ & $\begin{array}{l}\text { Isoelectric point } \\
\text { (pl) }\end{array}$ & $\begin{array}{l}\text { Molecular weight } \\
(\mathrm{kDa})\end{array}$ & $\begin{array}{l}\text { Sub cellular } \\
\text { localization }\end{array}$ \\
\hline COCPS & OMP05060.1 & 797 & 14 & 15 & 5.70 & 91.81 & Chloroplast \\
\hline COKS & OMO77892.1 & 737 & 11 & 12 & 5.55 & 84.15 & Chloroplast \\
\hline COKO & OMO74862.1 & 494 & 7 & 8 & 6.45 & 56.24 & Chloroplast \\
\hline COKAO & OMP12279.1 & 501 & 7 & 8 & 9.15 & 58.19 & $\begin{array}{l}\text { Endoplasmic } \\
\text { reticulum }\end{array}$ \\
\hline CoGA200x1 & OMP00493.1 & 388 & 2 & 3 & 5.34 & 43.80 & Cytoplasm \\
\hline CoGA200x2 & OMO97972.1 & 379 & 2 & 3 & 5.96 & 43.14 & Cytoplasm \\
\hline CoGA200x3 & OMO89803.1 & 390 & 2 & 3 & 5.75 & 44.56 & Cytoplasm \\
\hline CoGA200x4 & OMO89804.1 & 383 & 2 & 3 & 5.66 & 43.61 & Cytoplasm \\
\hline CoGA200x5 & OMO89806.1 & 360 & 2 & 3 & 8.09 & 41.05 & Cytoplasm \\
\hline CoGA200x6 & OMO89807.1 & 383 & 2 & 3 & 5.85 & 43.55 & Cytoplasm \\
\hline CoGA200X7 & OMO56094.1 & 383 & 2 & 3 & 6.12 & 43.40 & Cytoplasm \\
\hline CoGA3OX1 & OMO80533.1 & 347 & 1 & 2 & 6.38 & 39.00 & cytoplasm \\
\hline COGA3OX2 & OMO66852.1 & 368 & 1 & 2 & 7.66 & 40.78 & Cytoplasm \\
\hline COGA3OX3 & OMO57996.1 & 362 & 1 & 2 & 6.20 & 40.63 & Cytoplasm \\
\hline CoGA2OX1 & OMP12162.1 & 338 & 2 & 3 & 5.79 & 37.32 & Cytoplasm \\
\hline CoGA2OX2 & OMP04507.1 & 305 & 3 & 4 & 6.77 & 35.12 & Cytoplasm \\
\hline COGA2OX3 & OMO92642.1 & 333 & 2 & 3 & 8.80 & 37.50 & cytoplasm \\
\hline CoGA2OX4 & OMO72387.1 & 359 & 2 & 3 & 7.05 & 40.53 & Cytoplasm \\
\hline CoGA2OX5 & OMO65667.1 & 341 & 2 & 3 & 7.64 & 37.83 & Cytoplasm \\
\hline CoGA20x6 & OMO64910.1 & 310 & 2 & 3 & 5.03 & 35.06 & Cytoplasm \\
\hline CoGA2OX7 & OMO64911.1 & 332 & 2 & 3 & 5.66 & 37.99 & Cytoplasm \\
\hline COGA2OX8 & OMO58522.1 & 332 & 2 & 3 & 5.58 & 36.71 & Cytoplasm \\
\hline
\end{tabular}

GA oxidases are from Isopenicillin $\mathrm{N}$ synthase family which contains a $\mathrm{Fe}^{2+}$-binding motif, an HXD dyad near the amino terminus and a histidine towards the carboxyl terminus [42]. Multiple sequence alignments and 3D structure exhibited that the position of these amino acids were His-249, Asp-251, and His-305 for jute GA20 oxidases (Fig. 4a; Additional file 2: Figure S1) which were His-223, Asp-225 and His-280 for GA3 oxidases
(Fig. 4b, Additional file 2: Figure S2). As a member of Isopenicillin $\mathrm{N}$ synthase, GA2 oxidases also carry the same motif. Positions of the two His and one Asp residues were at 200, 257 and 202 respectively for C-19 GA2ox (Fig. 4c, Additional file 2: Figure S3). Similarly, C-20 GA2ox contained the HXD dyad at 214 and 217 positions and the second His at 268 (Fig. 4d, Additional file 2: Figure S4). Besides, GA20 oxidases possessed two

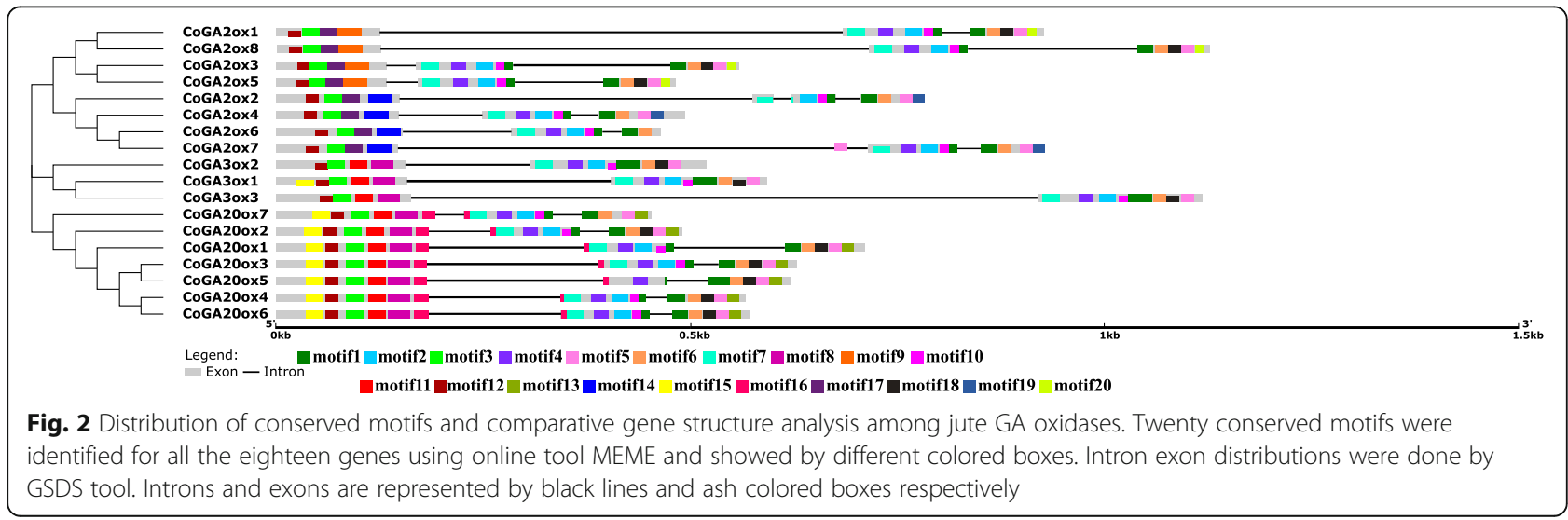



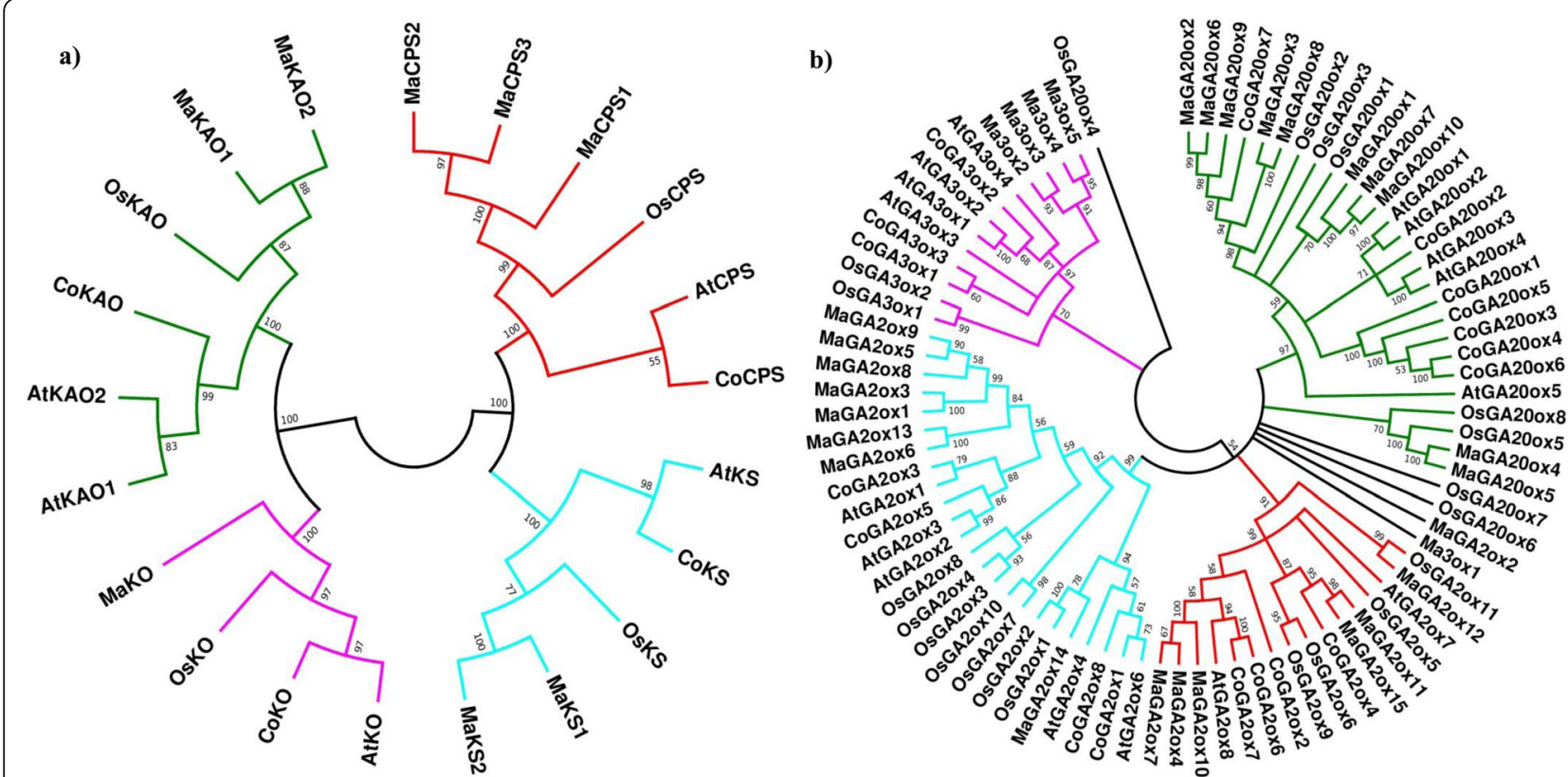

Fig. 3 Phylogenetic position of GA metabolism genes. Both the phylogeny tree (a) for early GA bio synthesis genes and (b) for GA oxidase genes were produced with MEGA 7.0 using the sequences of Oryza sativa (Os), Arabidopsis thaliana (At) and Musa acuminata (Ma) and Corchorus olitorius (Co). The accession numbers of protein sequences are mentioned in Additional file 1: Table S1

binding site, NYYPXCXXP sequence at 232-240 position and LPWKET at 151-156 position. However, only two sequences of jute, CoGA20ox2 and CoGA20ox7 had the exact binding site LPWKET while rest five possessed a little bit different sequences, for example- CoGA20ox1, CoGA20ox4, and CoGA20ox6 had M, F, and F respectively instead of $\mathrm{L}$ in the first position (Additional file 2: Figure S1).

Jute GA oxidases shared some common motifs like motif no. 1, 3, 6, 12 (Fig. 2). Motif no. 4 was also common except in CoGA2ox2. Similarly, motif no. 2, 7 and 10 were available in all the 17 sequences excluding in CoGA20ox5. Signature motifs for GA20 oxidases were motif no. 13 and 16 while such special motif was not found for GA3 oxidases. As both GA20ox and GA3ox had motif no. 8 and 11, they were probably the function leading motif for these sub families. Unique motifs for C-19 GA2ox and C-20 GA2ox proteins were motif no. 9 and 14 respectively. Both C-19 GA2ox and C-20 GA2ox contained motif no. 17, which was absent in GA20 oxidases and GA3 oxidases. So, this exclusive motif may account for the function difference of GA2ox gene family. Motif sequences are given in Additional file 1: Table S3. Though motif distribution pattern was different in different subgroups, it was very similar within the subgroup of different species which indicates that members from the same subfamily have similar gene structures.
Finding the cis-acting element in the promoters of GA biosynthetic genes

Cis-acting elements play a vital role in gene transcription by facilitating the binding of transcription factors. To elucidate the regulatory mechanism of GA metabolism genes, $1000 \mathrm{bp}$ upstream sequences from each transcription start site were searched for cis-elements. Available cis-regulatory elements were classified in four categories-(a) plant hormone regulation, (b) biotic and abiotic stress, (c) plant growth and development and (d) promoter function (Additional file 2: Figure S5). Stress (biotic and abiotic) responsive cis-elements were the maximum in jute GA biosynthesis genes and out of those light-responsive elements (ATC motif, G-box, GTmotif, TCT- motif, 3-AF1 binding site, Box 4, TCCCmotif, ATCT-motif, AE-box, CAG motif, MRE, I-box, GATA-motif, Box ii, CAG-motif, GA-motif, LAMPelement, chs-CMA2a) were the highest. The number of motifs involved in hormonal regulation was the second largest group after stress-responsive motifs in jute GA metabolism genes. Moreover, they contained motifs related to different phytohormone like Salicylic acid (TCA-element, SARE), Auxin (TGA element), Abscisic acid (ABRE), Gibberellic acid (TATC-box, p-box, GARE-motif). Interestingly, out of eighteen GA oxidases only seven genes- CoGA20ox2, CoGA20ox7, CoGA3ox2, CoGA2ox3, CoGA2ox5, CoGA2ox6 and CoGA2ox7 contained the motif p-box (Additional file 2: Figure S5). 

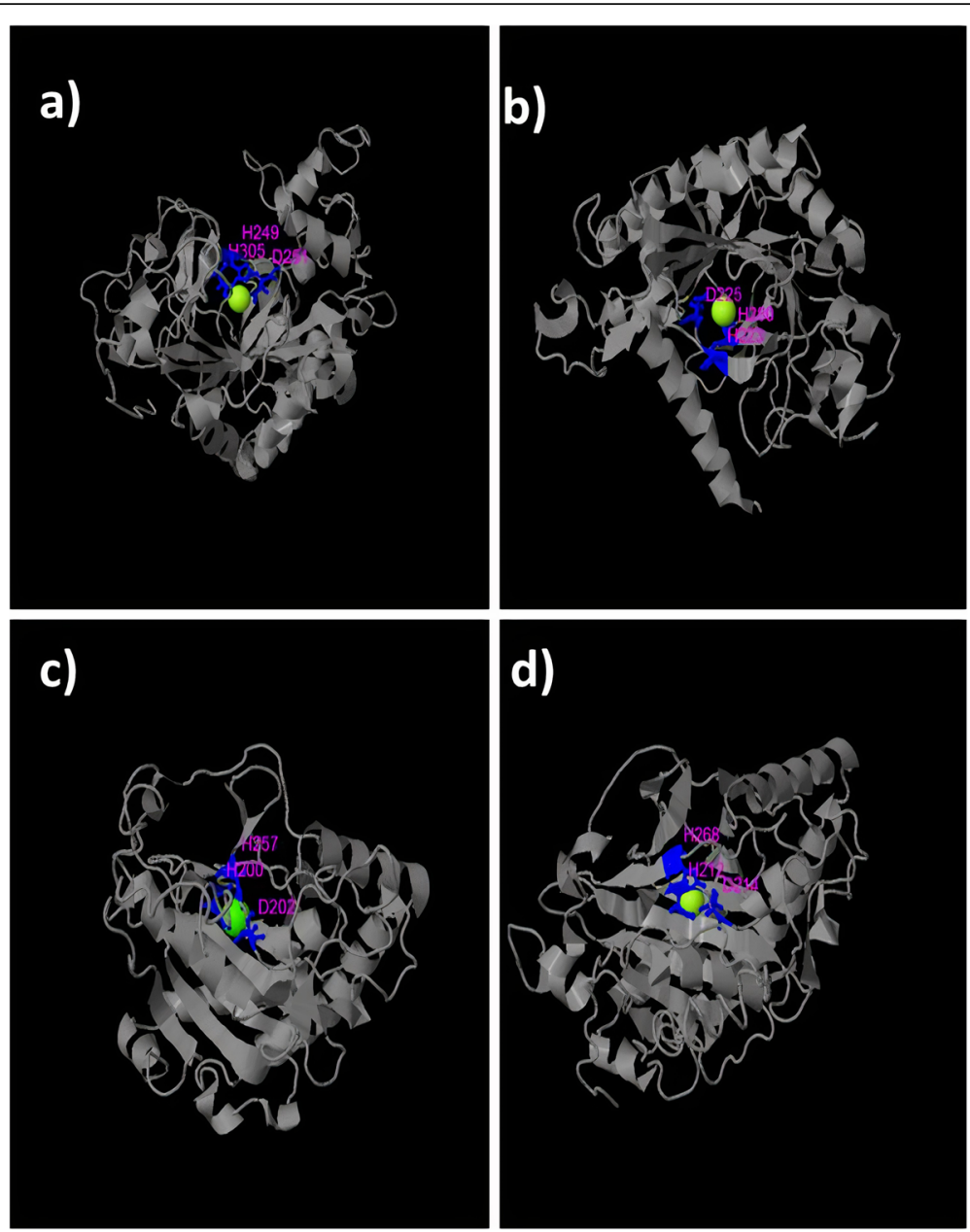

Fig. 4 3D structures of jute GA oxidases showing Fe2+ binding motif. The structure of (a) CoGA20ox1- representative of GA20 oxidases, (b) CoGA3ox1- representative of GA3 oxidases, (c) CoGA2ox8- representative of C-19 GA2 oxidases, (d) CoGA2ox4- representative of C-20 GA2 oxidases were modeled by I-TASSER server

However, jute GA biosynthesis genes had the least number of cis-acting elements for plant growth and development (CAT-box, O2-site, GCN4_motif). Available cis-regulatory elements in GA promoter region and their description are given in Additional file 1: Table S4.

\section{Gene ontology annotation (GO)}

The GO analysis implied that most of the jute GA biosynthesis genes involved in the oxidation-reduction processes. They also participated in flower development and unidimensional cell growth (Fig. 5a). These genes also had a wide range of molecular functions like gibberellin 20-oxidase, gibberellin 3-beta-dioxygenase, C-19 gibberellin 2-beta-dioxygenase, C-20 gibberellin 2-betadioxygenase activity. In addition, they also had magnesium, iron, and heme-binding capacity (Fig. 5b).

\section{Chromosomal localization and duplication analysis}

To know the distribution pattern of GA biosynthesis genes in different chromosomes, we mapped them on the seven chromosomes of jute and found that most of the genes were located on chromosome 3 and chromosome 4 (Fig. 6). Four genes including $\mathrm{CoKS}$, CoKAO, CoGA3ox3, and CoGA2ox8 were not mapped to any of the jute chromosomes, since, draft assemble of jute only anchored $\sim 60 \%$ of the total genome.

Duplication is an important mechanism in the process of evolution. Two gene clusters of tandem duplication and three gene pair of segmental duplication were found in jute GA biosynthesis genes (Fig. 6). $\mathrm{Ka} / \mathrm{Ks}$ ratio was calculated to explore the trend of gene divergence after duplication. Ninety percent of jute GA biosynthesis genes had undergone through purifying selection which means functional divergence might occur before 
(a)

- Gibberellin biosynthetic process

- Unidimensional cell growth

- Gibberellin catabolic process (b)

- Magnesium ion binding

Monooxygenase activity

- Heme binding

Gibberellin 3-beta-dioxygenase activity

C-20 gibberellin 2-beta-dioxygenase activity

- Terpene synthase activity

- Iron ion binding

Gibberellin 20-oxidase activity

- C-19 gibberellin 2-beta-dioxygenase activity

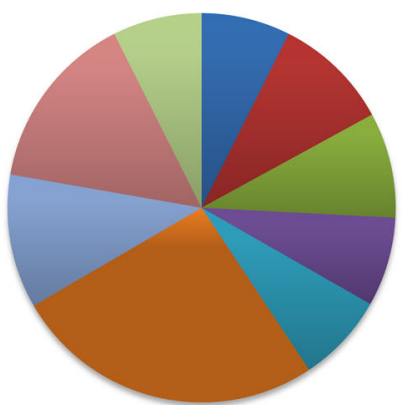

Fig. 5 Gene ontology annotation of GA bio synthesis genes. a biological process and (b) molecular function

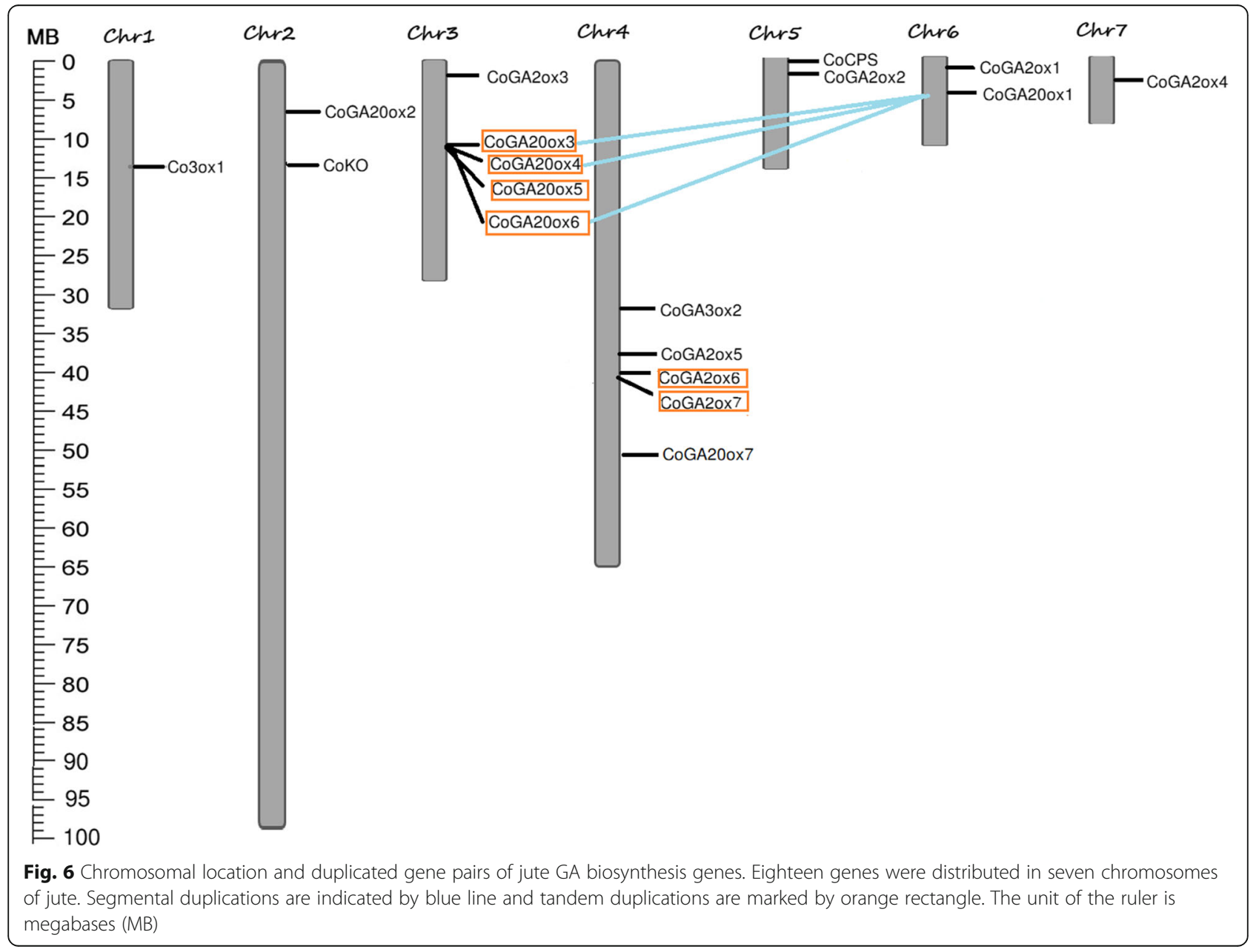


Table $2 \mathrm{Ka} / \mathrm{Ks}$ estimation for the duplicated gene pairs

\begin{tabular}{|c|c|c|c|c|c|c|c|}
\hline Duplicated gene 1 & Duplicated gene 2 & $\mathrm{Ka}$ & Ks & $\mathrm{Ka} / \mathrm{Ks}$ & Purifying selection & Duplicate type & Age (MYA) \\
\hline CoGA200X1 & CoGA200X3 & 0.1569 & 0.2655 & 0.5910 & Yes & segmental & 8.85 \\
\hline CoGA200x1 & CoGA200X4 & 0.1621 & 0.3047 & 0.5320 & Yes & segmental & 10.16 \\
\hline CoGA200X1 & CoGA200x6 & 0.1597 & 0.3076 & 0.5192 & Yes & segmental & 10.25 \\
\hline COGA200X3 & CoGA200X4 & 0.0651 & 0.0898 & 0.7250 & Yes & tandem & 3.00 \\
\hline CoGA200x3 & CoGA200X5 & 0.1043 & 0.1494 & 0.6981 & Yes & tandem & 4.98 \\
\hline CoGA200X3 & CoGA200X6 & 0.0728 & 0.0710 & 1.0261 & No & tandem & 2.36 \\
\hline COGA200X4 & CoGA200x5 & 0.1449 & 0.1844 & 0.7858 & Yes & tandem & 6.14 \\
\hline CoGA200X4 & CoGA200x6 & 0.0147 & 0.0398 & 0.3689 & Yes & tandem & 1.32 \\
\hline COGA200x5 & COGA200X6 & 0.1460 & 0.1803 & 0.8097 & Yes & tandem & 6.01 \\
\hline CoGA20x6 & CoGA20x7 & 0.0837 & 0.2748 & 0.3047 & Yes & tandem & 9.16 \\
\hline
\end{tabular}

duplication events (Table 2). The time of the duplication event was calculated using synonymous substitution rate. The result revealed that divergence time for segmental duplication was 8.85 to 10.25 million years ago (MYA) and it was from 1.32 to 9.16 MYA for tandem duplicated genes (Table 2).

\section{Spatial expression analysis}

After identifying different genes of jute GA biosynthesis pathway we checked their expression in root, leaf, flower, stick, bark and top internode to know whether they had organ-specific expression pattern. In general, the early steps genes showed ubiquitous expression in all the organs analyzed. CoKAO had higher expression compared to other three genes. CoCPS, CoKS and CoKAO had similar expression pattern having the highest expression in top internode and the lowest expression in leaf. The expression of $\mathrm{CoKO}$ gene was higher in root, bark and internodes while it has its lower expression in leaf (Fig. 7). Notably, most of the genes (CoCPS, CoKO, CoKAO) had their highest expression in top internode in comparison to other tissues.

Interestingly, most of the later steps genes (11 genes) were inactive in our considered samples. Only seven of them CoGA20ox2, CoGA20ox7, CoGA3ox2, CoGA2ox1, CoGA2ox3, CoGA2ox5, and CoGA2ox7 had expression in different tissues. To justify our result, we investigated the expression of GA biosynthesis genes by using the RNA-seq data published by Islam et al. [41]. It was very similar to our qRT-PCR data (Additional file 2: Figure S6). Moreover, we also performed PCR analysis with cDNA of these unexpressed genes using qRT-PCR primers (Additional file 1: Table S5) and no band was observed in the gel (data not shown).

For GA20ox family, CoGA20ox7 was expressed broadly in all the tissues examined while CoGA20ox 2 showed tissue specificity having expression only in leaf, bark, and stick. The expression of CoGA20ox7 was

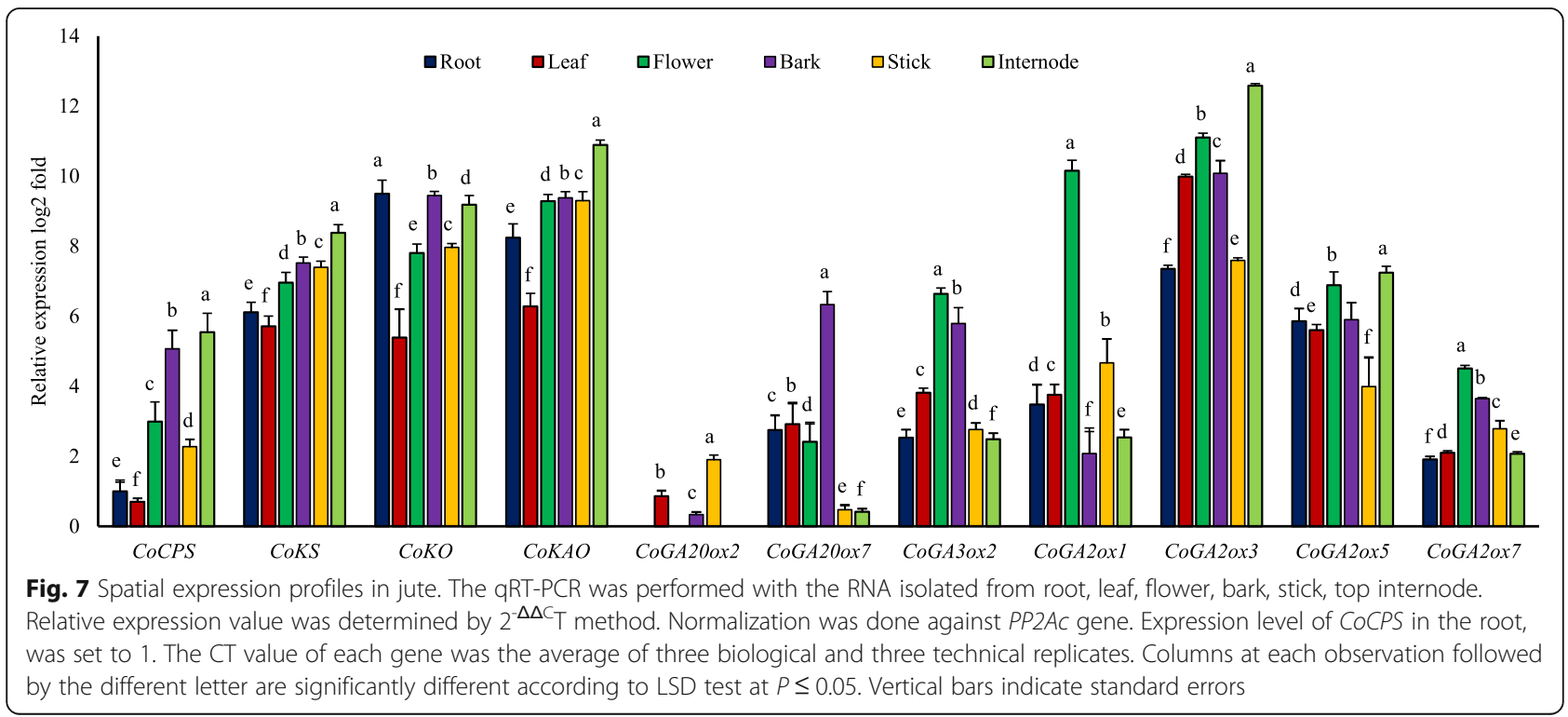


predominant in bark followed by leaf and root. Overall, CoGA20ox2 had lower expression than CoGA20ox7 in almost all the tested parts. CoGA3ox2, the only active gene of GA3 oxidase family, exhibited its highest expression in flower and the lowest expression in the top internode (Fig. 7). Among four GA2 oxidases, CoGA2ox3 appeared to have the highest expression and it was mostly expressed in top internode. Overall, CoGA2ox5 had a moderate expression having higher expression in internode and flower and less in stick. Though expression level of CoGA2ox1 was high in flower, it was actually a weekly expressed gene. The CoGA2ox7 had the least expression in all the considered tissue in comparison to other GA2 oxidases (Fig. 7). On the basis of expression pattern, it may be hypothesized that CoGA20ox7, CoGA3ox2, CoGA2ox3 and CoGA2ox5 were the key regulators for GA production in jute and CoGA20ox2, CoGA2ox1, CoGA2ox7 were the least important ones.

\section{Morphological effect of exogenous treatments}

Plants were treated with exogenous GA, PAC and G + P solutions to confirm GA's effect on the jute plant. The results suggested that plant height was significantly increased in GA treated plant (Fig. 8a and b) than the controls. On the other hand, the reverse scenario was found in the case of PAC treatment. In G + P treatment, the plants had moderate height, lower than GA treated plants and higher than PAC treated plants. A similar trend was also found in the case of internode length and node number (Fig. 8c and d). GA increased node number and internode length while PAC caused lower number of nodes and shorter internode in comparison to control. These results indicated that GA has a significant role in plant development.

\section{Response of GA biosynthesis genes to exogenous treatments}

Thirty days old jute plants were treated with distilled water (con), GA, PAC, and G + P in order to know how GA metabolism pathway genes react to exogenous spray. In this experiment, only the top internode was collected as RNA sample for qRT-PCR analysis. CoCPS and CoKAO were down-regulated while CoKS was a little bit up-regulated in comparison with control in all the treatments. CoKO remained unchanged in GA treated samples whereas it was up-regulated in PAC treatment and down regulated in $\mathrm{G}+\mathrm{P}$ treatment (Fig. 9a-d).

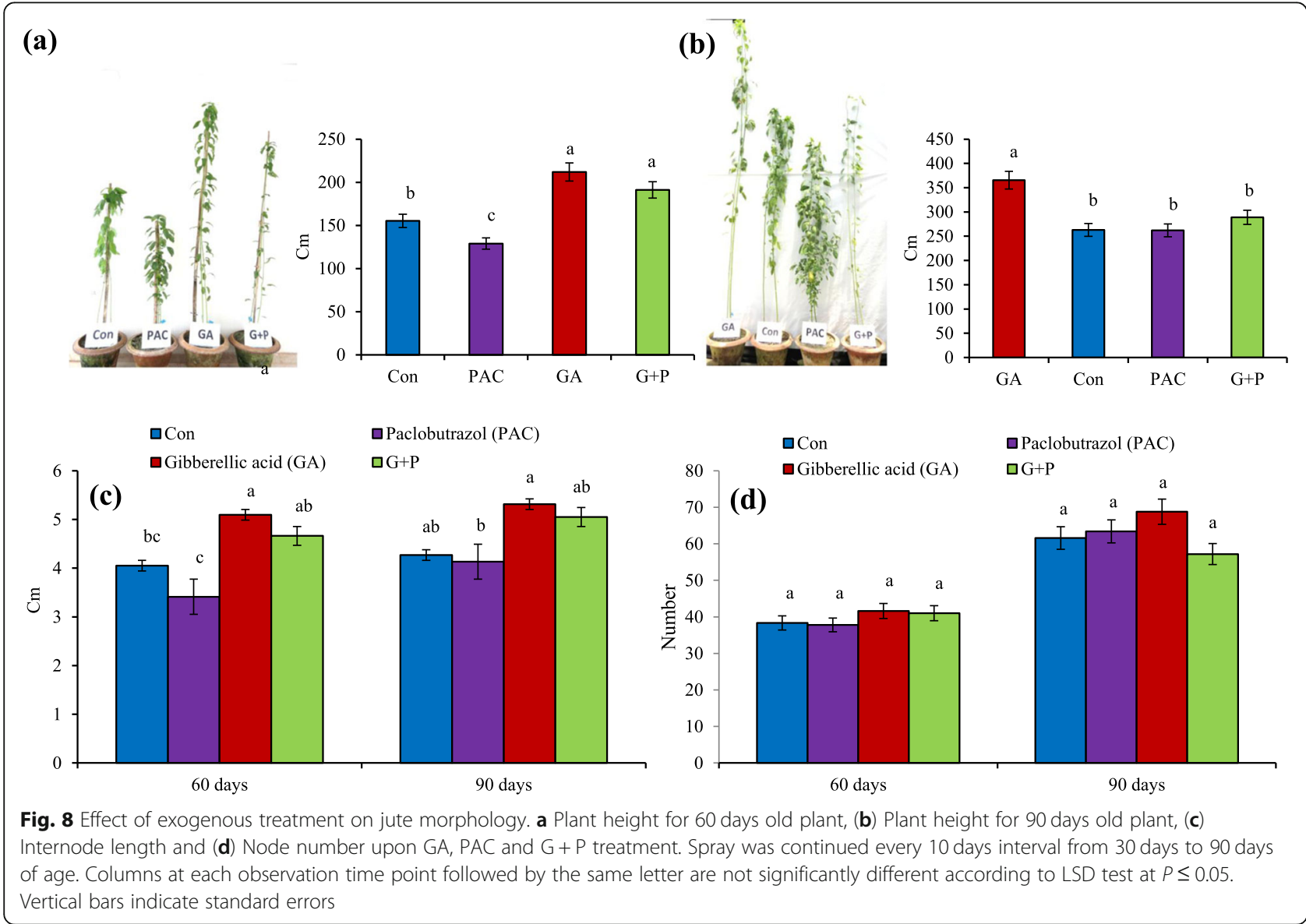




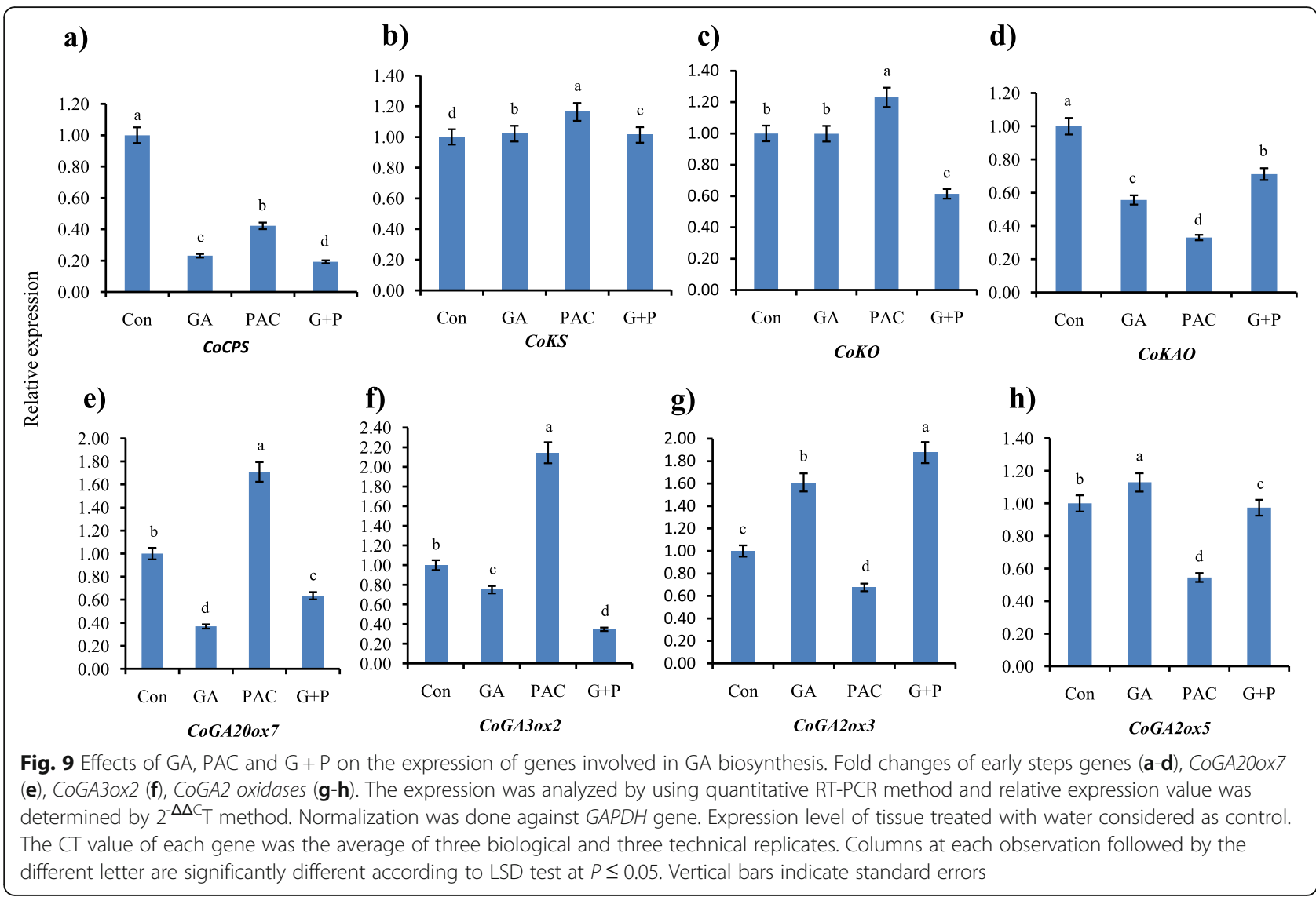

Based on spatial expression analysis, CoGA20ox7, CoGA3ox2, CoGA2ox3, and CoGA2ox5 were selected to check their response to GA, PAC, and G + P treatments. CoGA200x7 was down-regulated upon GA and $\mathrm{G}+\mathrm{P}, 0.63$ times and 1.07 times respectively whereas they were significantly up-regulated upon PAC treatment, 1.3 times compare to the control. The expression level of CoGA3ox2 also followed the same trend having 0.25 and 1.7 times down-regulation and 1.3 times up-regulation than the control after GA, G + P and PAC treatment respectively (Fig. 9e-f). On the contrary, GA and G+P spray enhanced the expression level of CoGA2ox3, CoGA2ox5 while PAC spray decreased their expression level (Fig. 9g-h). Overall, the expression changes were lower in GA treatments than in PAC and G + P.

\section{Discussion}

Gene identification, phylogenetic relationship, motif analysis, and gene structure

\section{Early steps enzymes}

Enzymes involved in the early stages of GA metabolism pathway in jute are encoded by single genes. This finding is fully consistent with previous study where it was concluded that early steps of GA metabolism pathway genes are encoded by single or few genes [13]. For example- Arabidopsis has one copy of CPS, $K S$, and $K O$ and two copies of $K A O$ genes [43]. Finding from phylogenetic relationship and gene structure analysis reveals jute has more close relation with Arabidopsis than rice and banana (Fig. 3a) which justify that early step enzymes could be divided into monocot and dicot [17]. Subcellular localization by Plant-mPLoc showed that CoCPS, CoKS, and CoKO were located in chloroplast and CoKAO was located in the endoplasmic reticulum. This result is very much harmonious with previous studies. For example - AtCPS and AtKS1 are localized in chloroplast while AtKO is remained in the outer envelope of chloroplast and AtKAO1, AtKAO2 are destined in the endoplasmic reticulum [44].

\section{Later steps enzymes}

We have identified 18 candidate genes for three types of GA oxidases in jute. Among them, seven GA20 oxidases, three GA3 oxidases, and eight GA2 oxidases are available in jute while Arabidopsis possess five GA20 oxidases, four GA3 oxidases, and seven GA2 
oxidases. Rice genome has 8, 2 and 11 copies of GA20ox, GA30x and GA2ox respectively. So, GA20ox and GA2ox have a larger number of genes which proves a more dynamic evolutionary route of these two groups. This also causes relaxed selective pressure or loosened constraints in the process of evolution. On the other hand, GA3ox has fewer numbers of genes that means the family is more conserved than GA20ox and GA2ox [17].

The phylogenetic analysis of GA oxidases showed that they are segregated into four distinct subgroups (GA20ox, GA3ox, C-19 GA2ox, and C-20 GA2ox). This result is quite similar to Arabidopsis, rice, maize and soybean [17, 38, 45]. Identification of unique motifs for all the subgroups further justified the classification. In each subgroup, it was observed that GA oxidases from the same species were more closely related than GA oxidases from other species which ultimately meant that GA oxidase expansion occurred early in the evolution of this protein family.

Though the catalytic domain was well conserved within GAox family proteins, there was variation in gene structure in different subfamilies within jute. More similarity in gene structure with more closely related members of the subfamily suggests selective diversification of the GAox family. The majority of the GAox subfamilies in jute contained three exons. This also emphasizes on selective diversification. Some members of the jute GAox family had relatively longer introns. These introns may have been evolved from unequal crossing over [45].

\section{Morphological effect of exogenous treatment}

GA treated jute plants were relatively tall whereas PAC treated plants were relatively dwarf. This finding is similar to other fiber crops like hemp [46] and flax [47]. Similarly, GA caused increased node number and internode length. These observations proved that GA influences vegetative stem growth by increasing both the number and length of the internodes. GA causes increased cell elongation and division by inducing transcription of genes involved in these processes. As an example- in the elongating stem of rice and Arabidopsis, some of the genes encoding xyloglucan endotransglycosylases (XETs) and expansins have been up-regulated by GA [48-50]. XET is responsible for plasticity of the cell wall while expansins are involved in plant cell wall loosening. Some of the genes encoding for cyclindependent protein kinases also showed ectopic expression in intercalary meristem in rice upon GA treatment [51]. However, in $\mathrm{G}+\mathrm{P}$ treatment, plant height was moderate justifying that PAC inhibited plant growth mainly by decreasing GA biosynthesis and it was partially rescued by GA.
Tissue specificity of GA metabolism genes and their response to exogenous treatment

Jute GA biosynthesis genes showed obvious tissue specificity, similar to many other plants $[17,39,43]$. However, most of the GA oxidases genes of jute did not participate in GA biosynthesis. For example, among five GA20 oxidases of jute only two (CoGA20ox2 and CoGA20ox7) were expressed. This result ultimately proves the redundant functionality of GA oxidases [16]. Interestingly, promoter analysis of these genes showed that most of the expressed genes contain a specific cis-acting element that is p-box (Additional file 2: Figure S5). Therefore, pbox might have important role in the regulation of $G A$ oxidases. It was also noticeable that top internode was the mostly active tissue where most of the genes of GA metabolism pathway had their highest expression. These results indicate the regulation of GA biosynthesis at the tissue and organ level and also reveals that the localization of CoGA2ox3 and CoGA2ox5 expression within an organ affects both GA homeostasis and GA levels, and thereby growth. Generally, growing organs like developing leaves, expanding internodes contain the highest amount of bioactive GA [52] and these organs have a high expression level of GA-biosynthetic genes [53]. Consequently, for checking the effect of exogenous GA, PAC, and G + P treatments, samples were collected only from top internode. In this experiment, CoGA20ox7, CoGA3ox2 were down-regulated in GA treatment and showed reverse expression in PAC treated samples. The plant has its own homeostasis system to maintain optimum GA level to continue its natural growth and development through a mechanism named feedback regulation [54]. When plants were treated with exogenous GA, the quantity of endogenous GA was increased and CoGA20ox7, CoGA3ox2 decreased their expression to lower the synthesis of GA. Likewise, plants treated with PAC had a lower amount of endogenous GA since PAC inhibits GA synthesis. As a result, CoGA20ox7, CoGA3ox2 increased their expression to minimize the effect of PAC. On the other hand, CoGA2ox3, CoGA2ox5 which were responsible for inactivating active GA, showed just reverse expression pattern. This was due to another homeostasis mechanism named feed forward regulation of GA2ox genes [20-22]. Overall, both in up-regulation and down-regulation GA had weaker effect in gene expression than PAC which ultimately means that in control condition jute had optimum level of GA in top internode. According to Acheampong et al. [55] when a specific organ has minimal amount of GA for its growth, it shows high response to PAC and minimal changes to GA. For $\mathrm{G}+\mathrm{P}$ treatment, plants were firstly treated with PAC that means they had a low amount of GA. However, after 2 days when they were treated with GA, the effect of PAC 
was minimized. Therefore, in these samples, the gene expression change was similar but higher than GA treated samples. For early steps genes, we did not get any feedback regulation. Indeed this is already proven that early steps genes are not under feedback regulation [23]. However, these genes showed altered transcript level upon GA, PAC and G+P treatment. This phenomenon is difficult to explain as two of them CoCPS and CoKS interact with (E,E)-4,8,12-trimethyltrideca-1,3,7,11-tetraene (TMTT) biosynthesis pathway [56]. Moreover, PAC competes with $\mathrm{KO}$ for inhibiting GA biosynthesis [57]. Therefore, the reasons for this phenomenon need to be experimentally evidenced.

Though jute GA oxidases genes changed their expression to maintain GA homeostasis in jute still we got different morphology like increased plant height, internode length upon continuous GA spray which was also a common phenomenon for carrot [58] and apple [59]. Actually treating jute with GA and PAC in every 10 days altered endogenous GA level of jute and alter hormone homeostasis, thus influence plant growth.

\section{Conclusion}

In this study, we have identified 22 candidate genes for seven enzymes involved in GA metabolism in jute and classified them into seven gene families including CoCPS, CoKS, CoKO, CoKAO, CoGA20ox, CoGA3ox, and CoGA2ox. Phylogenetic analysis, motif distribution pattern and gene structure study proved that GA metabolism genes in jute maintain conservation and divergence. Moreover, through spatial expression analysis, we have proved their tissue specificity and found top internode as the most active zone where most of the GA metabolism genes have comparatively higher expression. We also found that only later steps genes are feedback regulated. Combined these results we have finally identified four key regulatory genes. This comprehensive analysis of GA biosynthesis genes will be a foundation for the genetic improvement of jute and other closely related plants with agricultural importance.

\section{Methods}

\section{Sequence acquisition, alignment, and phylogenetic tree construction}

All the sequences involved in GA biosynthesis were retrieved from TAIR (The Arabidopsis Information Resource, http://www.Arabidopsis.org), Rice Genome Annotation Project Database (http://www.rice.plantbiology.msu.edu/), The Banana Genome Hub (http://banana-genome.cirad.fr/blast) and the NCBI (http://www. ncbi.nlm.nih.gov/). To identify homologs of these genes in jute, BLAST search (BLASTP) was carried out against
Corchorus olitorius cultivar: O-4 genome (https://www. ncbi.nlm.nih.gov/bioproject/215141). Sequences were accepted from BLAST which had an expected threshold lower than 1e-30. All the sequences are listed in Additional file 1: Table S1. Expasy ProtParam tool (http:// web.expasy.org/protparam/) was used to determine physical and chemical properties like the molecular weight, theoretical pI and so on. Subcellular localization was investigated through Plant-mPLoc (http://www. csbio.sjtu.edu.cn/bioinf/plant-multi/). Multiple sequence alignments of the Arabidopsis, rice, banana, and jute were conducted by Clustal Omega tool (http://www.ebi. ac.uk/Tools/msa/clustalo/). An unrooted phylogenetic tree was generated by using the neighbour-joining (NJ) method with poisson correction, pairwise deletion and 1000 bootstrap replicates parameters by MEGA version 7 [60].

\section{Domain, motif, gene structure, and 3D structure determination}

The protein sequences of predicted jute GA metabolism genes were subjected to Pfam (http://pfam.sanger.ac.uk/ search) and SMART (http://smart.emblheidelberg.de/) database to identify their conserved domain. To obtain their characteristic motif, Multiple Expectation Maximization for Motif Elicitation (MEME) (http:// meme-suite.org/) was employed with the parameters as follows- maximum numbers of motifs was set to 20, the optimum motif width was $6-50$ amino acid, and 0 or 1 single motif in each sequence of the model. The phylogenetic trees together with annotation file in Generic Feature Format Version 3 (GFF3) were prepared for visualization of the Gene Structure Display Server (GSDS) 2.0 (http://gsds.cbi.pku.edu.cn/) to determine the intron-exon structure. Phylogenetic tree, conserved motif and gene structures were integrated by using a Scalable Vector Graphics (SVG) editor Inkscape 0.92.4 (https://inkscape.org/). The three dimensional (3D) structure with $\mathrm{Fe}^{+2}$ binding site was predicted through an online tool named I-TASSER (Iterative Threading Assembly Refinement) (http://zhanglab.ccmb.med. umich.edu/I-TASSER/).

\section{Promoter analysis and gene ontology annotation}

For promoter analysis, 1000 bp upstream from the transcription start site was retrieved from the Corchorus olitorius genome by using custom Perl scripts. Those putative cis-acting elements were investigated through an online promoter analysis tool named PlantCare (http://bioinformatics.psb.ugent.be/webtools/plantcare/ $\mathrm{html} /$ ). Gene ontology analysis was performed with Blast2GO software (https://www.blast2go.com/). The GO terms for each of the two main categories- biological 
process and molecular function were obtained from sequence similarity with the default parameters.

\section{Chromosomal localization and duplication analysis}

Distribution of the GA biosynthesis genes in the different chromosome of jute was represented with a schematic diagram. Generally, proteins that had more than $70 \%$ identity and separated by no more than five other genes within $100 \mathrm{~kb}$ region were considered as tandem duplications [61]. Similarly, genes separated by more than five genes were considered as segmental duplication.

\section{Determination of $\mathrm{ka} / \mathrm{ks}$ ration}

Amino acid sequences of duplicated gene pairs were aligned by using Clustal Omega program. Ka (the number of nonsynonymous substitutions per nonsynonymous site) and Ks (the number of synonymous substitutions per synonymous site) ratio was calculated by PAL2NAL (http://www.bork.embl.de/pal2nal/) through the codeml program in PAML. In general, $\mathrm{Ka} / \mathrm{Ks}=1$ means neutral selection; $\mathrm{Ka} / \mathrm{Ks}<1$ means purifying selection; $\mathrm{Ka} / \mathrm{Ks}>1$ means accelerated evolution with positive selection [62]. The divergence time ' $t$ ' was estimated with the equation, " $\mathrm{t}=\mathrm{Ks} / 2 \mathrm{r}$ " where $\mathrm{r}=1.5 \times 10^{-8}$ according to Islam et al. [41].

\section{Plant materials}

Tossa jute (C. olitorius cv. O-4) was used in this experiment for both morphological and molecular analysis. Seeds were collected from Gene Bank of Bangladesh Jute Research Institute and its accession number was 1808. They were grown in the greenhouse of BARJ under $16 \mathrm{~h}$ light and $8 \mathrm{~h}$ dark at $32^{\circ} \mathrm{C}$ in 36 earthen pots $(30 \times 30$ $\mathrm{cm})$ and each of the pot contained four seeds. The earthen pots were prepared with a mixture of vermiculite and organic soil (1:1). Among them, 12 pots were used for morphological data collection, 12 pots were used for spatial expression analysis and the remaining were used for checking the effect of GA, PAC and G + P spray. The pots were maintained in the greenhouse in a control environment till the end of the experiments.

\section{GA, PAC, G + P treatment}

GA (LOBA Chemie) and Paclobutrazol (PAC)- the inhibitor of GA (Sigma-Aldrich, Germany) solution were prepared at $100 \mathrm{ppm}$ with distilled water and $0.1 \%$ tween 20 (wetting agent). In the case of $\mathrm{G}+\mathrm{P}$ spray, plants were sprayed with PAC before 2 days of GA spray and this combined treatment $(G+P)$ was used to verify the relation between the effect of GA and PAC.

\section{Morphological data collection}

At the age of 30 days, plants were sprayed individually with tween 20 formulated GA, PAC, and G + P solution at $100 \mathrm{ppm}$ concentration by using a low-pressure handwand sprayer. During spray, $60 \%$ humidity and $25-27^{\circ} \mathrm{C}$ temperature were maintained. Control plants were treated with distilled water containing $0.1 \%$ Tween 20 . The spray was continued at 10 days interval from 30 days to 90 days of plant age. Plant height of all treated plants along with the control was measured by a meter scale at 60 days aged (4th dose of spray) and 90 days aged plants (7th dose of spray). Internode length was determined by dividing the total length of the plant with a total node number.

\section{RNA sample collection}

For conducting spatial gene expression analysis, root, leaf (5th leaf), bark and stick ( $9 \mathrm{~cm}$ from top), top internode (rosette to 5th leaf- around $5.5 \mathrm{~cm}$ ) samples were collected from 40 days old plants. To check the effect of exogenous spray, top internode (rosette to 5th leaf) was collected as RNA sample after $12 \mathrm{~h}$ of spray with 100 ppm of GA, PAC and G+ P. All the sampled organs were immediately frozen at liquid nitrogen in the greenhouse and preserved at $-80^{\circ} \mathrm{C}$.

\section{RNA isolation and CDNA preparation}

For RNA isolation one gram of each sample was crushed in liquid nitrogen to a fine powder through a mortar and pestle. Finally, RNA was extracted by the modified CTAB method mentioned in Ahmed et al. [63]. RNA quality was checked by using $1 \%$ gel electrophoresis followed by quantification with NanoDrop 2000 spectrophotometer (NanoDrop, ThermoFisher Scientific, USA). All the RNA samples were treated with amplification grade DNase I (Sigma-Aldrich, Germany) to avoid DNA contamination. After that, this pure RNA was used to prepare first-strand complementary DNA (cDNA) using the RevertAid First Strand cDNA Synthesis Kit (Thermo Fisher Scientific, USA) according to the manufacturer's instructions. Subsequently, the samples were incubated with RNase H (Thermo Fisher Scientific, USA) to degrade the RNA strand of any RNA-DNA hybrids according to the manufacturer's instructions and preserved at $-20^{\circ} \mathrm{C}$ until use.

Primer design and reverse transcription quantitative realtime PCR (qRT-PCR)

Specific qRT-PCR primers were designed by the online tool IDT (https://sg.idtdna.com/pages/tools/primerquest) and Genscript (www.genscript.com) for all the genes involved in GA biosynthesis pathway except for CoGA20ox3, CoGA20ox4, CoGA20ox5, and CoGA20ox6. Only one primer was designed for these four genes since 
the CDS region of these four sequences had almost 80$85 \%$ similarity. All the primers are shown in Additional file 1: Table S5. After that, qRT-PCR was performed with PowerUp ${ }^{\text {tw }}$ SYBER $^{\text {tw }}$ Green Master Mix (Thermo Fisher Scientific, USA) by maintaining manufactures protocol. The total reaction mixture was $20 \mu \mathrm{l}$ and each reaction contained $40 \mathrm{ng}$ of cDNA. It was carried out in a 96 well plate on Quantstudio 5 (Applied Biosystems) with the condition- $50^{\circ} \mathrm{C}$ for $2 \mathrm{~min}, 95^{\circ} \mathrm{C}$ for $2 \mathrm{~min}, 95^{\circ} \mathrm{Cfor} 15 \mathrm{~s}, 60^{\circ} \mathrm{C}$ for $1 \mathrm{~min}$ for 45 cycles. For all the qRT-PCR reaction there were three biological replications and three technical replications with negative control (no template). A melting curve was also generated to check primer specificity.

The qRT-PCR data was analyzed with the ${ }^{2-}{ }^{\Delta \Delta C} \mathrm{~T}$ method [64]. The result was expressed as fold change after normalization with reference genes. Though housekeeping genes are usually used as reference genes for normalization, they may change significantly, depending on the tissue, environmental conditions and species. According to Hossain et al. [32] catalytic subunit of protein phosphatase 2A (PP2Ac) gene was used as reference gene for expression analysis in different tissues. However, to observe, the expression changes of GA biosynthesis genes upon GA, PAC and G + P treatment, there was no such study for jute. Therefore, an experiment was conducted to find the housekeeping gene which was not GA regulated (data not shown) and more stable within different treated samples and found glyceraldehyde 3-phosphate dehydrogenase (GAPDH) as the desired one.

\section{Supplementary information}

Supplementary information accompanies this paper at https://doi.org/10. 1186/s12870-020-02512-2.

Additional file 1: Table S1. Accession numbers of GA metabolism genes used in this paper. Table S2. Multilevel consensus sequences for the MEME defined motifs observed among early steps GA biosynthesis genes from rice, Arabidopsis, banana and jute. Table S3. Multilevel consensus sequences for the MEME defined motifs observed among GA oxidases from rice, Arabidopsis, banana and jute. Table S4. Activities of cis-acting elements in the promoter region of GA biosynthesis genes. Table S5. Primer sequences of the reference gene and GA metabolism genes for qRT-PCR in this study.

Additional file 2: Figure S1. Multiple alignments of GA20 oxidases from jute. (Green colored box shows GA substrate binding site, brown colored shows 2-oxoglutarate-binding motif (LPWKET), black colored boxes show $\mathrm{Fe}^{2+}$-binding motif). Figure S2. Multiple alignments of GA3 oxidases from jute. (Black colored boxes show the $\mathrm{Fe}^{2+}$-binding motif). Figure S3. Multiple alignments of C-19 GA2 oxidases from jute. (Black colored boxes show the $\mathrm{Fe}^{2+}$-binding motif). Figure S4. Multiple alignments of C-20 GA2 oxidases from jute. (Black colored boxes show the $\mathrm{Fe}^{2+}$-binding motif). Figure S5. Cis-acting elements present in the promoter region of GA biosynthetic genes. Cis-acting elements responsible for plant hormone regulation (a) for plant growth and development (b) for biotic and abiotic stress response (c) for promoter function (d). 1000 bp upstream sequence from the start point was considered. Figure S6. Heat map showing relative expression of genes involved in GA biosynthesis. Samples were taken from 4-day-old seedlings, fiber cells, very young seedlings before bolting and fiber cells. The heat map of normalized RNA-seq data was prepared from three biological replicates from fiber cells and whole seedlings of C. olitorius and C. capsularis. Gene expression was measured by quantified transcription levels (fragments per kilobase of exon model per million mapped reads, FPKM) derived from RNA-seq analysis. Heat scale, log2 (FPKM). In order to calculate the log2 (FPKM) values of individual genes, all of the original FPKM values were added by a pseudo-count of 1 .

\section{Abbreviations}

GA: Gibberellin; CPS: ent-copalyl diphosphate synthase; KAO: ent-kaurenoic acid oxidase; KO: ent-kaurene oxidase; KS: ent-kaurene synthase; GA20ox: GA20oxidase; GA2ox: GA2-oxidase; GA3ox: GA3-oxidase; GGDP: Geranylgeranyl diphosphate; TPSs: Terpene synthasese; XET: Xyloglucan endotransglycosylases; NCBI: National Center for Biotechnology Information; qRT-PCR: quantitative Real-Time Polymerase Chain Reaction; PAC: Paclobutrazol; CTAB: Cetyltrimethylammonium bromide; 2ODD: 2-oxoglutarate-dependent dioxygenases; PP2Ac: Catalytic subunit of protein phosphatase 2A; GAPDH: Glyceraldehyde 3-phosphate dehydrogenase; TMTT: (E,E)-4,8,12-trimethyltrideca-1,3,7,11-tetraene

\section{Acknowledgements}

The authors are thankful to all the researchers of Basic and Applied Research on Jute Project for their cooperation and special thanks to Rasel Ahmed and Md. Sabbir Hossain for their cordial support.

\section{Authors' contributions}

UH and MSI designed the research. MSH, RJ and SJ supervised the experiment and revised the manuscript. UH and SMTK performed bioinformatics analysis. UH and MRA performed the experiment, RNA extraction, qRT-PCR and analyzed results. KKB performed statistical analysis and reviewed the paper. UH, MRA and MM collected morphological data and RNA sample for molecular analysis; MSI, UH and MRA wrote and critically reviewed the manuscript. All authors have read and approved the manuscript.

\section{Funding}

This study did not receive any formal funding.

\section{Availability of data and materials}

The datasets supporting the conclusions and description of a complete protocol can be found within the manuscript and its additional files. The datasets used and/or analysed during the current study are available from the corresponding author on reasonable request.

\section{Ethics approval and consent to participate}

Not applicable.

\section{Consent for publication}

Not applicable.

\section{Competing interests}

The authors declare that they have no competing interests.

\section{Author details}

${ }^{1}$ Basic and Applied Research on Jute Project, Bangladesh Jute Research Institute, Manik Mia Avenue, Dhaka 1207, Bangladesh. ${ }^{2}$ Department of Biotechnology and Genetic Engineering, University of Development Alternative, Dhaka, Bangladesh. ${ }^{3}$ Bangladesh Jute Research Institute, Manik Mia Avenue, Dhaka 1207, Bangladesh.

Received: 3 March 2020 Accepted: 22 June 2020

Published online: 01 July 2020

\section{References}

1. Tyler L, Thomas SG, Hu J, Dill A, Alonso JM, Ecker JR, et al. DELLA proteins and gibberellin-regulated seed germination and floral development in Arabidopsis. Plant Physiol. 2004;135(2):1008. 
2. Ayele BT, Ozga JA, Kurepin LV, Reinecke DM. Developmental and embryo axis regulation of gibberellin biosynthesis during germination and young seedling growth of pea. Plant Physiol. 2006;142(3):1267-81.

3. Junttila O, Jensen E, Pearce D, Pharis R. Stimulation of shoot elongation in Salix pentandra by gibberellin GA3; activity appears to be dependent upon hydroxylation to GA1 via GA3. Physiol Plant. 2006;84:113-20.

4. Hedden P, Proebsting WM. Genetic analysis of gibberellin biosynthesis. Plant Physiol. 1999;119(2):365.

5. Blázquez MA, Green R, Nilsson O, Sussman MR, Weigel D. Gibberellins promote flowering of Arabidopsis by activating the LEAFY promoter. Plant Cell. 1998;10(5):791.

6. Serrani JC, Sanjuán R, Ruiz-Rivero O, Fos M, García-Martínez JL. Gibberellin regulation of fruit set and growth in tomato. Plant Physiol. 2007;145(1):246

7. Statistical Bulletin-2014. Rome: Food and Agriculture Organization of the United Nations; 2014.

8. MacMillan J. Occurrence of gibberellins in vascular plants, fungi, and bacteria. J Plant Growth Regul. 2001;20(4):387-442.

9. Olszewski N, Sun TP, Gubler F. Gibberellin signaling: biosynthesis, catabolism, and response pathways. Plant Cell. 2002;14(Suppl):S61-80.

10. Sakamoto T, Miura K, Itoh H, Tatsumi T, Ueguchi-Tanaka M, Ishiyama K, et al. An overview of gibberellin metabolism enzyme genes and their related mutants in Rice. Plant Physiol. 2004;134(4):1642.

11. Huang Y, Wang X, Ge S, Rao G-Y. Divergence and adaptive evolution of the gibberellin oxidase genes in plants. BMC Evol Biol. 2015;15:207.

12. Yamaguchi S. Gibberellin biosynthesis in Arabidopsis. Phytochem Rev. 2006; 5:39-47.

13. Hedden P. Gibberellin biosynthesis. Wiley: Chichester; 2012. https://doi.org/ 10.1002/9780470015902.a0023720.

14. Grennan AK. Gibberellin metabolism enzymes in rice. Plant Physiol. 2006; 141(2):524-6.

15. Phillips AL, Ward DA, Uknes S, Appleford NEJ, Lange T, Huttly AK, et al. Isolation and expression of three gibberellin 20-oxidase cDNA clones from Arabidopsis. Plant Physiol. 1995;108(3):1049.

16. Mitchum MG, Yamaguchi S, Hanada A, Kuwahara A, Yoshioka Y, Kato T, et al. Distinct and overlapping roles of two gibberellin 3-oxidases in Arabidopsis development. Plant J. 2006;45(5):804-18.

17. Chen J, Xie J, Duan Y, Hu H, Hu Y, Li W. Genome-wide identification and expression profiling reveal tissue-specific expression and differentiallyregulated genes involved in gibberellin metabolism between Williams banana and its dwarf mutant. BMC Plant Biol. 2016;16(1):123.

18. Xu YL, Li L, Gage DA, Zeevaart JA. Feedback regulation of GA5 expression and metabolic engineering of gibberellin levels in Arabidopsis. Plant Cell. 1999;11(5):927-36.

19. Carrera $\mathrm{E}$, Jackson SD, Prat $\mathrm{S}$. Feedback control and diurnal regulation of gibberellin 20-oxidase transcript levels in potato. Plant Physiol. 1999;1 19(2):765.

20. Thomas SG, Phillips AL, Hedden P. Molecular cloning and functional expression of gibberellin 2- oxidases, multifunctional enzymes involved in gibberellin deactivation. Proc Natl Acad Sci U S A. 1999;96(8):4698-703.

21. Elliott RC. Feed-forward regulation of gibberellin deactivation in pea. J Plant Growth Regul. 2001;20(1):87-94.

22. Rieu I, Eriksson S, Powers SJ, Gong F, Griffiths J, Woolley L, et al. Genetic analysis reveals that C19-GA 2-oxidation is a major gibberellin inactivation pathway in Arabidopsis. Plant Cell. 2008;20(9):2420-36.

23. Helliwell CA, Sheldon CC, Olive MR, Walker AR, Zeevaart JA, Peacock WJ, et al. Cloning of the Arabidopsis ent-kaurene oxidase gene GA3. Proc Natl Acad Sci U S A. 1998;95(15):9019-24.

24. Oikawa T, Koshioka M, Kojima K, Yoshida H, Kawata M. A role of OsGA20ox1 , encoding an isoform of gibberellin 20-oxidase, for regulation of plant stature in rice. Plant Mol Biol. 2004;55(5):687-700.

25. Fleet CM, Yamaguchi S, Hanada A, Kawaide H, David CJ, Kamiya Y, et al. Overexpression of AtCPS and AtKS in Arabidopsis confers increased entkaurene production but no increase in bioactive gibberellins. Plant Physiol. 2003;132(2):830-9.

26. Coles JP, Phillips AL, Croker SJ, Garcia-Lepe R, Lewis MJ, Hedden P. Modification of gibberellin production and plant development in Arabidopsis by sense and antisense expression of gibberellin 20-oxidase genes. Plant J. 1999;17(5):547-56.

27. Huang S, Raman AS, Ream JE, Fujiwara H, Cerny RE, Brown SM. Overexpression of 20-oxidase confers a gibberellin-overproduction phenotype in Arabidopsis. Plant Physiol. 1998;118(3):773-81.
28. Carrera E, Bou J, Garcia-Martinez JL, Prat S. Changes in GA 20-oxidase gene expression strongly affect stem length, tuber induction and tuber yield of potato plants. Plant J. 2000;22(3):247-56.

29. Biemelt S, Tschiersch H, Sonnewald U. Impact of altered gibberellin metabolism on biomass accumulation, lignin biosynthesis, and photosynthesis in transgenic tobacco plants. Plant Physiol. 2004;135(1):25465

30. Hu YX, Tao YB, Xu ZF. Overexpression of Jatropha gibberellin 2-oxidase 6 (JcGA2ox6) induces dwarfism and smaller leaves, flowers and fruits in Arabidopsis and Jatropha. Front Plant Sci. 2017;8:2103.

31. Basra A. Plant Growth Regulators in Agriculture and Horticulture: Their Role and Commercial Uses. New York: Food Products Press; 2000.

32. Hossain MS, Ahmed R, Haque MS, Alam MM, Islam MS. Identification and validation of reference genes for real-time quantitative RT-PCR analysis in jute. BMC Mol Biol. 2019:20(1):13.

33. Jewel MRJ. Golden dream for golden fibre. In: The daily Sun; 2016.

34. Stant MY. The effect of gibberellic acid on cell width and the cell-wall of some phloem Fibres. Ann Bot. 1963;27(1):185-96.

35. Stant MY. The effect of gibberellic acid on fibre-cell length. Ann Bot. 1961; 25(4):453-62.

36. Lange T, Kappler J, Fischer A, Frisse A, Padeffke T, Schmidtke S, et al. Gibberellin biosynthesis in developing pumpkin seedlings. Plant Physiol. 2005;139(1):213.

37. Davidson SE, Swain SM, Reid JB. Regulation of the early GA biosynthesis pathway in pea. Planta. 2005;222(6):1010-9.

38. Song J, Guo B, Song F, Peng H, Yao Y, Zhang Y, et al. Genome-wide identification of gibberellins metabolic enzyme genes and expression profiling analysis during seed germination in maize. Gene. 2011;482(1-2): 34-42.

39. Du Q, Li C, Li D, Lu S. Genome-wide analysis, molecular cloning and expression profiling reveal tissue-specifically expressed, feedbackregulated, stress-responsive and alternatively spliced novel genes involved in gibberellin metabolism in salvia miltiorrhiza. BMC Genomics. 2015;16:1087.

40. Dayan J, Schwarzkopf M, Avni A, Aloni R. Enhancing plant growth and fiber production by silencing GA 2-oxidase. Plant Biotechnol J. 2010; 8(4):425-35

41. Islam MS, Saito JA, Emdad EM, Ahmed B, Islam MM, Halim A, et al. Comparative genomics of two jute species and insight into fibre biogenesis. Nat Plants. 2017;3(2):16223.

42. Roach PL, Clifton IJ, Fulop V, Harlos K, Barton GJ, Hajdu J, et al. Crystal structure of isopenicillin $\mathrm{N}$ synthase is the first from a new structural family of enzymes. Nature. 1995;375(6533):700-4.

43. Ogawa M, Hanada A, Yamauchi Y, Kuwahara A, Kamiya Y, Yamaguchi S. Gibberellin biosynthesis and response during Arabidopsis seed germination. Plant Cell. 2003;15(7):1591.

44. Helliwell CA, Sullivan JA, Mould RM, Gray JC, Peacock WJ, Dennis ES. A plastid envelope location of Arabidopsis ent-kaurene oxidase links the plastid and endoplasmic reticulum steps of the gibberellin biosynthesis pathway. Plant J. 2001;28(2):201-8.

45. Han F, Zhu B. Evolutionary analysis of three gibberellin oxidase genes in rice, Arabidopsis, and soybean. Gene. 2011;473(1):23-35.

46. Atal CK. Effect of gibberellin on the fibers of hemp. Econ Bot. 1961;15(2): 133-9.

47. Rastogi DA, Siddiqui A, Mishra B, Srivastava M, Pandey R, Misra P, et al. Effect of auxin and gibberellic acid on growth and yield components of linseed (Linum usitatissimum L.). Crop Breed Appl Biot. 2013;13:136-43.

48. Cho H-T, Kende $\mathrm{H}$. Expression of expansin genes is correlated with growth in Deepwater rice. Plant Cell. 1997;9:1661-71.

49. Uozu S, Tanaka-Ueguchi M, Kitano H, Hattori K, Matsuoka M. Characterization of XET-related genes of rice. Plant Physiol. 2000;122:853-9.

50. Xu W, Campbell P, Vargheese AV, Braam J. The Arabidopsis XET-related gene family: environmental and hormonal regulation of expression. Plant J. 1996;9:879-89.

51. Fabian T, Lorbiecke R, Umeda M, Sauter M. The cell cycle genes cycA1;1 and cdc2Os-3 are coordinately regulated by gibberellin in planta. Planta. 2000; 211:376-83.

52. Smith V, Knatt C, Gaskin P, Reid J. The distribution of gibberellins in vegetative tissues of Pisum sativum L. I. Biological and biochemical consequences of the le mutation. Plant Physiol. 1992;99:368-71. 
53. Silverstone AL, Chang C, Krol E, Sun TP. Developmental regulation of the gibberellin biosynthetic gene GA1 in Arabidopsis thaliana. Plant J. 1997; 12(1):9-19.

54. Thomas SG, Rieu I, Steber CM. Gibberellin metabolism and signaling. Vitam Horm. 2005;72:289-338.

55. Acheampong AK, Hu J, Rotman A, Zheng C, Halaly T, Takebayashi Y, et al. Functional characterization and developmental expression profiling of gibberellin signalling components in Vitis vinifera. J Exp Bot. 2015;66(5): 1463-76.

56. Ma Y, Yuan L, Wu B, Li X, Chen S, Lu S. Genome-wide identification and characterization of novel genes involved in terpenoid biosynthesis in salvia miltiorrhiza. J Exp Bot. 2012;63:2809-23.

57. Rademacher W. Inhibitors of gibberellin biosynthesis: applications in agriculture and horticulture. In: Gibberellins. New York: Springer New York; 1991. p. 296-310.

58. Wang GL, Que F, Xu ZS, Wang F, Xiong AS. Exogenous gibberellin altered morphology, anatomic and transcriptional regulatory networks of hormones in carrot root and shoot. BMC Plant Biol. 2015;15:290.

59. Zhang $S$, Zhang D, Fan $S$, Du L, Shen $Y$, Xing $L$, et al. Effect of exogenous GA3 and its inhibitor paclobutrazol on floral formation, endogenous hormones, and flowering-associated genes in 'Fuji' apple (Malus domestica Borkh.). Plant Physiol Biochem. 2016;107:178-86.

60. Kumar S, Stecher G, Tamura K. MEGA7: molecular evolutionary genetics analysis version 7.0 for bigger datasets. Mol Biol Evol. 2016;33(7):1870-4.

61. Shu Y, Liu Y, Zhang J, Song L, Guo C. Genome-wide analysis of the AP2/ERF superfamily genes and their responses to abiotic stress in Medicago truncatula. Front Plant Sci. 2015;6:1247.

62. Hurst LD. The Ka/Ks ratio: diagnosing the form of sequence evolution. Trends Genet. 2002;18(9):486

63. Ahmed R, Hossain MS, Haque M, Alam M, Islam MS. Modified protocol for RNA isolation from different parts of field-grown jute plant suitable for NGS data generation and quantitative real-time RT-PCR. Afr J Biotechnol. 2019;18: 647-58.

64. Livak KJ, Schmittgen TD. Analysis of relative gene expression data using real-time quantitative PCR and the 2 (-Delta Delta C (T)) method. Methods. 2001;25(4):402-8.

\section{Publisher's Note}

Springer Nature remains neutral with regard to jurisdictional claims in published maps and institutional affiliations.

Ready to submit your research? Choose BMC and benefit from:

- fast, convenient online submission

- thorough peer review by experienced researchers in your field

- rapid publication on acceptance

- support for research data, including large and complex data types

- gold Open Access which fosters wider collaboration and increased citations

- maximum visibility for your research: over $100 \mathrm{M}$ website views per year

At $\mathrm{BMC}$, research is always in progress.

Learn more biomedcentral.com/submissions 